\title{
HISTÓRIA DA EDUCAÇÃO E MARXISMO EM DUAS TRAJETÓRIAS INTELECTUAIS DO SÉCULO XX: BRIAN SIMON E MARIO ALIGHIERO MANACORDA
}

\author{
Marisa Bittar ${ }^{1}$ \\ Universidade Federal de São Carlos (UFSCar)
}

\section{RESUMO}

Este artigo é resultado de pesquisa realizada no Instituto de Educação da Universidade de Londres focalizando a trajetória de dois intelectuais marxistas europeus do século XX e sua contribuição para a História da Educação: o inglês Brian Simon (1915-2002) e o italiano Mario Alighiero Manacorda (1914-2013). Ambos viveram e elaboraram suas obras no mesmo período histórico e aderiram ao marxismo como resposta à escalada nazi-fascista na Europa engajando-se em lutas políticas pela democratização da educação depois da Segunda Guerra Mundial. A pesquisa baseou-se em fontes bibliográficas, entrevistas e em documentos do arquivo "Brian Simon" que se encontra no Instituto de Educação da Universidade de Londres. Na Itália foi realizado um encontro com Manacorda e examinados documentos do Instituto Gramsci. Considerando a similitude das duas trajetórias, os objetivos da pesquisa foram: 1. Conhecer a interpretação marxista empregada pelos dois autores; 2. Averiguar a relação de suas obras com o pensamento de Antonio Gramsci; 3. Estudar a contribuição de ambos para a circulação do conhecimento e a internacionalização da História da Educação. A pesquisa foi financiada pela FAPESP (2011-2012).

Palavras-chave: História da Educação, Marxismo; Brian Simon, Mario Manacorda, Antonio Gramsci.

\section{HISTORY OF EDUCATION AND MARXISM IN TWO TRAJECTORIES INTELLECTUALS OF THE TWENTIETH CENTURY: BRIAN SIMON AND MARIO ALIGHIERO MANACORDA}

\begin{abstract}
This article is the result of a survey conducted at the Institute of Education, University of London focusing on the thought of two European Marxist intellectuals of the twentieth century and their contribution to the History of Education: the English Brian Simon (1915 2002) and the Italian Mario Alighiero Manacorda (1914-2013). Both lived and produced their works in the same historical period and adhered to Marxism as a response to the escalating Nazi-Fascist in Europe and after the Second World War they engaged in political struggles for democratization of education. The research was based on literature sources, interviews as well as documents from file "Brian Simon" held at the Institute of Education, University of London. In Italy, a meeting was held with Manacorda and documents were examined at Gramsci Institute. Considering the similarity of their careers, the research objectives were: 1 . Knowing the Marxist interpretation of the two authors; 2. To investigate the relationship of the two authors with Antonio Gramsci's thought, 3. Observe the contribution of both to the circulation of knowledge and internationalization of the History of Education. The research was funded by FAPESP from 2011 to 2012.
\end{abstract}

Keywords: History of Education; Marxism; Brian Simon; Mario Manacorda; Antonio Gramsci. 


\section{Introdução}

Desde o final da ditadura militar (1985) o campo da História da Educação vem contribuindo com o processo de circulação e internacionalização do conhecimento e está organizado em todo o Brasil, atuando em três principais fóruns: o Grupo de Trabalho em História da Educação da ANPEd, criado em 1984, o Grupo de Estudos e Pesquisas "História, Sociedade e Educação no Brasil" (HISTEDBR), criado em 1986 e funcionando em todo o território nacional; a Sociedade Brasileira de História da Educação (SBHE), criada em 1999. Encontros, jornadas e congressos tem sido realizados regularmente e para as duas últimas entidades confluem participantes de todas as sub-áreas da Educação. Além disso, elas contam com a participação de pesquisadores estrangeiros convidados, fato que contribui para o intercâmbio internacional, a troca de experiências e diálogos sobre temas e tendências teóricas do campo.

No que diz respeito à organização internacional propriamente dita, pesquisadores da História da Educação brasileira constituem ampla maioria no Congresso Luso-Brasileiro de História da Educação (COLUBHE), que ocorre a cada dois anos de forma alternada entre o Brasil e Portugal e está em sua décima edição. Além disso, foi criado, em 1992, o Congresso Ibero-Americano de História da Educação Latino-Americana no qual o Brasil tem presença importante. Já a relação com países de língua inglesa é mais fraca.

Hoje, portanto, o intercâmbio é facilitado e intensificado por meio das associações científicas, além da Pós-Graduação, que está consolidada no Brasil. Mas até o início da década de 1980, a situação era diferente e a circulação do conhecimento entre os países dependia mais de inciativas pessoais, como acontecia, por exemplo, quando doutorados eram realizados fora do Brasil com prazos suficientes para que relações acadêmicas sólidas fossem estabelecidas, situação que resultava, depois, em projetos comuns. Foi o caso da frutífera relação com pesquisadores franceses, que, uma vez consolidada a Pós-Graduação brasileira, declinou. A expansão e consolidação da Pós-Graduação no Brasil se por um lado representou grande avanço para a pesquisa, por outro, tornou o seu horizonte mais nacional, reduzindo a dimensão internacional. Tal situação começou a mudar com a intensificação da revolução técnico-científica, que acelerou contatos e relações pela rede mundial de computadores. Além disso, de modo mais intenso nos últimos anos, as agências financiadoras de pesquisa têm insistido na internacionalização especialmente com países de língua inglesa, ênfase que começa a existir também dos Programas de Pós-Graduação. Por sua vez, desde o final da década de 1980, as associações científicas vêm atuando fortemente no caminho da internacionalização, hoje uma tendência marcante da área.

As trajetórias intelectuais aqui examinadas refletem esses momentos e transições. $\mathrm{O}$ intercâmbio com Manacorda ocorreu por iniciativa pessoal do ítalo-brasileiro Paolo Nosella nos anos de efervescência acadêmica no final da ditadura militar e anteriormente à ênfase dada à internacionalização pelas agências estatais brasileiras. Já o contato com a obra de Brian Simon, ocorreu por iniciativa desta pesquisa em conhecer o mais importante historiador da educação inglesa do século XX, um intelectual marxista quase desconhecido no Brasil. O fato de o projeto ter sido aprovado pela FAPESP e pelo CNPq pode ser um fator indicativo do interesse das principais agências de pesquisa brasileiras pelo intercâmbio da área de humanidades no Brasil com países de língua inglesa.

Desse modo, apresento resultados da pesquisa que teve como foco o estudo comparativo de duas trajetórias intelectuais da História da Educação no século XX: Brian 
Simon (1915-2002) e Mario Alighiero Manacorda (1914- 2013). Além da similaridade entre as duas trajetórias de vida, a opção por esses dois historiadores da educação deveu-se ao interesse em alargar a interlocução internacional no campo da História da Educação que, no caso brasileiro, tem sido desenvolvida principalmente com Portugal. A escolha foi baseada também no nexo entre as suas trajetórias pela democratização do ensino secundário em seus países, bem como no emprego do marxismo como método de interpretação da educação. Manacorda, um dos maiores intérpretes e divulgadores do pensamento de Antonio Gramsci, não escreveu uma autobiografia, fato que dificultou a reunião de fontes para a construção de sua trajetória. Brian Simon, ao contrário, organizou inúmeras fontes relativas à sua autobiografia e escreveu fartamente sobre ela, no entanto, publicou apenas o primeiro volume intitulado A life in Education (1988), deixando de publicar o relativo à militância política, especificamente a sua relação com o Partido Comunista da Grã-Bretanha que, segundo ele, já era sobejamente conhecida ${ }^{2}$. Tanto a parte publicada quanto a desconhecida do público serviram de fonte para esta pesquisa.

\section{Manacorda e o princípio da formação completa do ser humano}

Oriundo de uma família de grandes intelectuais, incluindo um irmão crítico literário, Mario Alighiero Manacorda, educador e historiador da educação, nasceu em Roma, em dezembro de 1914 e faleceu em fevereiro de 2013. Foi membro de associações de educadores, como a Associação de Defesa e Desenvolvimento da Escola Pública Italiana e integrante da seção pedagógica do Instituto Gramsci. Além disso, por longos anos, exerceu ativo trabalho editorial do jornal Rinascitá. Graduou-se na Universidade de Pisa em Literatura e Língua Italiana, especializando-se em estudos de filologia. Dono de uma impressionante capacidade de trabalho, que fazia questão de praticar "com o cérebro e com as mãos", pouco antes de falecer, Manacorda escrevia uma obra superior a mil páginas sobre o esporte, tema pelo qual era apaixonado e que derivava de sua concepção de educação como formação completa.

Ao longo da vida, Mario Alighiero Manacorda se distinguiu pela coerência teórica e particular atenção para com os problemas da escola e da cultura. Com Marx e a pedagogia moderna (1966) delineou o quadro de uma pedagogia que expressa a essência da obra marxiana colocando no centro do interesse a relação educação-trabalho e a formação omnilateral do ser humano. À reflexão do pensamento gramsciano, dedicou $\boldsymbol{O}$ princípio educativo em Gramsci (1970). Dentre os trabalhos de interesse histórico, destacam-se: La paideia di Achille (1971); Momenti di storia della pedagogia (1977); Storia dell'educazione dall'antichità ad oggi (1983); Scuola pubblica o privata? La questione scolastica tra Stato e Chiesa (1999); Cristianità o Europa? Come il Cristianismo salì al potere (2003). Na década de 1950, como diretor das edições Rinascitá, publicou a coleção Clássicos do marxismo. No Brasil, foram traduzidos Marx e a pedagogia moderna; $O$ princípio educativo em Gramsci (1990); História da Educação: da Antiguidade aos nossos dias (1989); Marx e a liberdade (2012).

Desde a juventude, Manacorda manteve posição crítica e anti-fascista, conforme relata sobre sua vida escolar no artigo La mia scuola sotto il fascismo. Depois da Guerra, engajou-se no Partido Comunista Italiano (PCI), incluindo atividades jornalísticas e editoriais no jornal L'Unitá principalmente sobre questões de educação e cultura, e foi membro do Comitê de Cultura do PCI.

Ao mesmo tempo em que se tornou um estudioso de Gramsci, Manaocrda demonstrou grande interesse pela experiência educacional russa, que o levou a escrever três 
volumes sobre o tema, os quais, no entanto, não foram publicados no Brasil. Nenhuma de suas obras está traduzida para o inglês e, segundo averiguamos em nossa pesquisa no Instituto de Educação da Universidade de Londres Manacorda é um autor desconhecido no campo da História da Educação no Reino Unido.

A relação de Mario Alighiero Manacorda com o campo da História da Educação no Brasil está associada ao término da ditadura militar. Em 1986, a convite de Paolo Nosella, seu amigo ítalo-brasileiro, ele participou das comemorações dos dez anos da Pós-Graduação em Educação da Universidade Federal de São Carlos, onde proferiu a palestra $\boldsymbol{O}$ industrialismo em Gramsci e o humanismo em Marx. Em uma proposital inversão dos termos, ele relacionou a Marx o que era mais frequentemente associado a Gramsci (o humanismo) e a Gramsci, o que era mais relacionado a Marx (o industrialismo). Com essa compreensão sobre os dois pensadores, Manacorda chamou a atenção para a educação como um processo de formação que deve ser amplo e total (omnilateral), criticando interpretações economicistas do marxismo e a visão determinista da escola como meramente reprodutora. A chave de sua abordagem nessa primeira visita acadêmica ao Brasil foi o humanismo e a capacidade de ação do sujeito para mudar a realidade.

Desde então, Manacorda ficou conhecido entre nós como um autor original, de formação erudita, um marxista avesso a dogmas deterministas. Na continuidade dessa circulação de conhecimento e intercâmbio acadêmico entre o Brasil e a Itália, em 1989, foi traduzido no Brasil o seu livro História da Educação: da Antiguidade aos nossos dias, distinguindo-se pela riqueza das fontes e originalidade de interpretação, fatores que logo o tornaram referência em Programas de Pós-Graduação em Educação e nos cursos de Pedagogia. Foi esse livro, de fato, o que mais difundiu o seu pensamento no Brasil. Nele, Manacorda se conduz por meio do conceito de formação omnilateral, que se constitui em eixo interpretativo, alinhavando todos os capítulos. Além disso, a escola de Estado é outro conceito-chave do livro.

Já conhecido pelos educadores brasileiros e tendo se tornado amigo deles, em 2006, nas comemorações dos vinte anos do Grupo de Estudos e Pesquisas "História, Sociedade e Educação no Brasil" (HISTEDBR), Manacorda gravou o DVD Aos educadores brasileiros, editado em 2007. Nessa ocasião, discorreu sobre as questões políticas e teóricas mais candentes que o século XX nos legou e sobre as suas grandes lições, como o nazi-fascismo e a Revolução Russa de 1917. Sobre os desacertos dessa, afirmou que o fim do "socialismo real" não o surpreendeu e acrescentou que foi fácil para o bloco hegemônico do capitalismo "sufocar a revolução, pois primeiro, ele a cercou, difamou, constrangeu-a a uma pressão interna, a gastar todos os seus recursos para se armar e acabou no isolamento" (Manacorda, 2007, p. 10). Quanto ao modelo de revolução bolchevique, ponderou: que não se deve mais fazer revoluções, mas devemos fazê-las todos os dias porque haverá sempre necessidade delas.

Parece contraditório, mas é assim (...) revolução significa mudança total dos sistemas sociais (...) creio que que se trata de um ensinamento marxista muito esquecido, quer pelos seus seguidores, quer pelos adversários. A assim chamada ditadura do proletariado, isto é, o exercício de um poder estatal, era uma medida insuficiente e, em todo caso, provisória. Marx queria a diminuição do poder do Estado em relação à sociedade civil. Esta era a sua lição (MANACORDA, 2007, p. 9). 
Além de questões teórico-políticas como esta, Manacorda discutiu as tendências da pesquisa em História da Educação, destacando a contribuição da Escola dos Annales que ampliou o conceito de fontes e inaugurou novos objetos de pesquisa, como a infância e as mulheres. Finalmente, enfatizou a necessidade de se manter a utopia de uma formação completa do ser humano (omnilateralidade) como um desafio que nos faz olhar para o alto.

Esse princípio é uma marca no pensamento e na atuação de Manacorda, desde pelo menos o final da Segunda Guerra Mundial. Em um contexto de reformas educacionais na Itália, ele defendeu o princípio da escola única para todos, combatendo a distinção entre a educação humanística para as elites e a escola preparatória para o trabalho, insistindo na necessidade de um novo humanismo que integrasse esses dois momentos formativos. Segundo ele, princípios gramscianos inspiraram a reforma da escola secundária italiana. Mas o ideal da formação completa é um princípio ainda não realizado, por isso, o imperativo categórico da educação pode ser assim enunciado: "Apesar de o ser humano lhe parecer, por natureza e de fato, unilateral, eduque-o com todo empenho em qualquer parte do mundo, para que se torne omnilateral" (Manacorda, 1989, p. 361).

Em 2012, Manacorda lançou no Brasil o livro Marx e a liberdade no qual discute a tradição liberal que era contemporânea a Marx no século XIX. Anteriormente, ele já havia chamado a atenção para uma "interpretação errônea de Marx, como se fosse um teórico do poder: era um teórico da liberdade" (Manacorda, 2006, p. 10). Quanto à concepção de educação, enfatizou que toda a reflexão de Marx centrou-se na questão da união entre ensino e trabalho visando o pleno desenvolvimento do ser humano: "que não seja sapateiro ou filósofo, mas ambos e algo mais omnilateralmente" (Manacorda, 2012, p. 79).

Para Manacorda, o tema da formação humana está presente nas reflexões de Marx e de Engels em três momentos específicos: no Manifesto Comunista (1848); em 1868 e também em 1875 (Crítica ao Programa de Gotha). Ainda segundo ele, nas três ocasiões "entrelaçando temas liberais e comunistas" (Manacorda, 2012, p. 86) Recordando a III tese de Marx sobre Feuerbach segundo a qual "o educador deve ser educado", Manacorda indaga: o que pode ser mais liberal? E responde que a força de Marx foi ter fundamentado ideais liberais e comunistas, "não sobre um desejo abstrato do dever ser, como acontece com os fundadores idealistas do liberalismo, mas pela constatação de um poder ser, não com base na moral, mas na realidade efetiva, e, portanto, pelos progressos da história" (Manacorda, 2012, p. 87)..

Com quase cem anos de idade, lendo o último livro de Eric Hobsbawn e outro sobre o Renascimento e a questão religiosa na Itália, encontrei Manacorda em Roma, em junho de 2012. Em sua mesa de trabalho, fazia exercícios de gramática russa e durante nossa conversa revelou a preocupação intelectual que mais o marcou. Voltando sempre ao eixo da sua concepção de educação como possibilidade de pleno desenvolvimento das capacidades do ser humano, ele indagou a certo momento: "Unilateralidade ou omnilateralidade? Platão ou Marx?" (Manacorda, 2012). Para ele, a unilateralidade persiste, mas o princípio da formação completa é milenar, estava em Platão, como estava em Aristóteles, mas foi Marx o primeiro a propor a possibilidade de formação completa para todos sem distinção de classe social, enquanto para Platão, haverá sempre a formação completa para o filósofo (dirigente) e apenas treinamento para o sapateiro (trabalhador braçal). Rigoroso com princípios e conceitos, fez questão de realçar que a sua própria interpretação da história da educação, baseada nesse fio condutor, não é exatamente gramsciana, uma vez que se trata de uma questão milenar fundada na Grécia Antiga e que atravessou os séculos.

Colocado a par da trajetória de Brian Simon, mostrou grande interesse pela história da educação na Inglaterra afirmando a importância do país quanto à questão cultural e a 
singularidade da questão religiosa. Ambos os fatores, segundo ele, "muito fortes e possivelmente tenham influenciado positivamente a educação inglesa" (Manacorda, 2012) Especificamente sobre Brian Simon e os pontos em comum com a sua própria trajetória, afirmou: "Bravo homem! Mas não o conheci".

Avesso a clichês e repetindo que "detesto a separação metafísica entre corpo e alma", foi assim que o vi pela última vez quando a porta do elevador se fechou deixando em minha memória a imagem de um homem ainda vigoroso, sorridente, crítico e planejando seu próximo livro.

\section{Brian Simon: "can education change society?"}

Brian Simon (1915-2002) foi o historiador da educação inglesa mais importante do século XX por ter desferido a mais consistente crítica à visão liberal predominante na história da educação britânica. O impacto de sua obra Studies in the History of Education em quatro volumes, cujo primeiro deles publicado em 1960, inaugurou uma interpretação marxista que marcaria fortemente esse campo do conhecimento em seu país. Por sua vez, o último volume, em 1991, caracteriza-se pela sequência às análises das políticas educacionais britânicas e crítica contundente à "era" Margaret Thatcher.

Ele estudou Economia e Língua Inglesa em Cambridge e foi professor de escolas secundárias antes de se tornar professor universitário. Aposentou-se em 1981 na Universidade de Leicester, onde ensinou História da Educação e continuou mantendo intensa atividade de pesquisador e de ativista pela "comprehensive school" (escola secundária única) até a sua morte. Além disso, foi um dos fundadores do International Standing Conference for the History of Education (ISCHE) e seu primeiro presidente (19781982), Nessa condição, aproximou pesquisadores do Leste europeu com o Ocidente.

Iniciei a pesquisa sobre a obra de Brian Simon no Instituto de Educação da Universidade de Londres sem ter como objetivo o estudo minucioso de sua vida, uma vez que pesquisadores ingleses já o haviam feito com grande competência, como foi o caso de Gary McCulloch. Meu objetivo principal foi estudar a forma de aplicação do marxismo em sua obra averiguando se havia ou não pontos em comum com a interpretação de Manacorda e, em segundo lugar, observar se em sua longa trajetória de luta pela "comprehensive school" teria havido a influência do pensamento de Gramsci.

A vida de Brian Simon se entrelaçou com a luta pela escola pública inglesa quando ele ainda era um jovem estudante da Universidade de Cambridge, em 1935, no Trinity College, "ponto focal de encontros políticos" (Simon, 1998, p. 10) ${ }^{3}$. Ali, Brian Simon tomou duas grandes decisões que definiriam o seu futuro: a primeira delas foi a adesão ao marxismo e ao Partido Comunista da Grã-Bretanha com outros jovens de sua geração entre os quais o irmão Roger Simon, como uma forma de resistência à escalada nazi-fascista na Europa. Na sua longa militância comunista, ocupou posições importantes na estrutura partidária tendo sido membro do Comitê Cultural e do Comitê Central mantendo-se próximo da União Soviética até pelo menos o início dos anos de 1970.

A segunda decisão, o interesse pela educação pública, diferentemente da primeira, não foi acompanhada por seus colegas, que nada sabiam sobre o sistema estatal de educação e suas escolas tendo sido educados fora dele. O seu caso, porém, era diferente. Ele provinha de uma família cujos princípios baseavam-se na tradição liberal, conforme mostraram McCulloch e Woodin ${ }^{4}$. Tanto o pai quanto a mãe foram fortemente engajados em atividades cívicas de seu tempo. O pai, Sir Ernest Simon, em 1934, criou a Association in Citizenship porque, segundo seu entendimento, nada naquele momento era mais necessário do que 
educar os estudantes para os deveres da cidadania a fim de construir um Estado democrático. Quanto à sua mãe, Shena Simon, trabalhou como ativo membro do Committee of Public Education in Manchester aderindo ao Partido Trabalhista como uma reação direta à política educacional conservadora em 1935. Mais tarde publicou o livro Three Schools or One? o primeiro a propagar na Inglaterra uma única escolar secundária para todos (comprehensive school). Por isso, ao comparar a sua experiência juvenil com a de seus colegas em Cambridge, Brian Simon assinalou que os problemas da educação e sua manutenção pelo Estado lhe eram familiares, mesmo que por segunda mão, isto é, a mão de sua mãe.

Para se tornar um professor da escola secundária e realizar uma carreira completa no mundo da educação, cursou estudos pós-graduados no Instituto de Educação da Universidade de Londres, em 1937, onde foi influenciado pelo criticismo que Fred Clark, o diretor, fazia ao sistema britânico de educação. Depois de terminada a Segunda Guerra Mundial, tornou-se professor na escola secundária engajando-se nos "reais problemas da educação, ensinando e aprendendo em escolas públicas" (Simon, 1998, p. 47). Desde os anos de 1940 até a "era Thatcher", combateu o sistema "tripartite" (escolas técnicas, secundário moderno, escolas humanísticas) persistindo contra o elitismo e considerando a "comprehensive school" uma vitória contra o privilégio. Por ter começado numa época de polaridade ideológica entre capitalismo e socialismo, essa campanha atravessou o ambiente britânico de "guerra fria na área acadêmica" (McCulloch, 2010, p. 445) e chegou aos tempos do neo-liberalismo recebendo dos opositores a crítica de ser uma causa que atendia a interesses soviéticos.

Para Brian Simon, a inequidade do sistema britânico de educação era sustentada nos testes de inteligência, que entre os anos 1920 e 1930 definiram políticas educacionais baseadas em um padrão hierárquico conhecido como "the 11 plus", isto é, testes que determinavam o futuro de uma criança aos 11 anos de idade, assegurando à minoria a escola secundária de humanidades "grammar school", acesso para a universidade. Apoiado nas teorias soviéticas da psicologia da aprendizagem, ele vinculou a campanha pela escola secundária comum à luta contra os testes de inteligência, pois eles justificavam a natureza seletiva do sistema. De acordo com Brian Simon, dois eram os mais sérios efeitos dessa prática: convencer os professores (com algumas exceções) de que a maioria das crianças tinha pouca habilidade para aprender, e prover às crianças uma auto-imagem negativa que afetava seu nível de aspiração e, consequentemente, suas conquistas. A teoria almejava, ao mesmo tempo, convencer os pais da "deficiência inata de seus filhos" (Simon, 1976, p. 172)

A forma de aplicação do marxismo para a interpretação da educação deve ser buscada na questão-chave que Brian Simon formulou e em como a respondeu em sua obra e campanha pela escola secundária única: "can education change society?" (a educação pode mudar a sociedade?) Criticando o otimismo do final do século XIX e o pessimismo determinista da sociologia do século XX, Brian Simon argumentou que a educação pode mudar a sociedade, assinalando que a atividade humana subjetiva é a chave para a mudança. Nesse sentido, suas críticas mais contundentes foram dirigidas a Samuel Bowles e Herbert Gintis (teoria da reprodução social) e Louis Althusser (ideologia). Em uma carta de 1975 ao Professor G. Swift, ele argumentou que a interpretação de Bowles e Gintis sobre escola e capitalismo na América não poderia ser generalizada e aplicada ao Reino Unido onde a história da educação e sua relação com as mudanças na estrutura de classes nos últimos 200 anos era muito diferente daquela sublinhada no livro de Gintis. E acrescentou: 
Eu poderia ir mais longe. Enquanto alguns naturalmente têm simpatia por essa abordagem, a interpretação me parece muito crua e simplista. As fontes históricas foram claramente selecionadas para provar um determinado ponto de vista [da reprodução] e é evidente que em muitos pontos a interpretação é anti-histórica. Por exemplo, me parece ridículo acusar Jefferson [presidente dos EUA, 1801-1809] de não ter sido um socialista! (SIMON, 1975).

Sua abordagem teórica também está bem evidente em Does Education Matter? livro que, segundo Clyde Chitty, seu contemporâneo na campanha pela "comprehensive school", é "a chave do seu marxismo, contra a visão determinista" (Chitty, 2012). De fato, Brian Simon trata da relativa autonomia que a educação pode exercer em relação aos demais fenômenos da sociedade, sem esquecer que a contradição principal da sociedade capitalista reside no antagonismo de classe. Insistindo na capacidade humana como um fator de mudança, escreveu:

É perfeitamente verdadeiro que Marx assegurou que as ideias dominantes em qualquer época são as ideias da classe dominante: se isso é aceito, segue-se que tais ideias inevitavelmente penetram na educação. Mas isso significa que, do mesmo modo, inevitavelmente, as ideias da classe dominante precisam sempre ser dominantes no campo da educação? Claramente isso depende de quem conduz o processo educacional (SIMON, 1977, p. 198. Grifo no original).

Partindo dessa premissa, combateu as teorias da reprodução e ministrou cursos em 1981 na Austrália sobre a teoria de Antonio Gramsci (hegemonia), Pierre Bourdieu, Samuel Bowles e Herbert Gintis (teoria da reprodução social) e Louis Althusser (ideologia). A partir desse material que se encontra no arquivo "Brian Simon" do Instituto de Educação, passei a buscar pistas que pudessem esclarecer a sua relação com o pensamento de Gramsci.

Aqui é preciso considerar o contexto histórico que caracterizava a circulação de conhecimento na Inglaterra, uma vez que a obra de Gramsci demorou a ser traduzida para o inglês e por isso a sua influência sobre os intelectuais de esquerda na Grã-Bretanha foi tardia, conforme escreveu Eric Hobsbawm em 1977:

Até essa década Gramsci permaneceu desconhecido fora de seu próprio país, uma vez que ele ainda não havia sido traduzido. Até mesmo as tentativas de publica as Cartas do Cárcere na Grã-Bretanha e nos Estados Unidos falharam. Com exceção de algumas pessoas com contatos pessoais na Itália e que liam italiano - a maioria comunistas - ele nem teria existido neste lado dos Alpes (HOBSBAWM, 1977, p. 205).

De fato, as fontes consultadas revelaram vínculos com os comunistas italianos, principalmente com Dario Ragazzini. De sua autoria, encontrei o texto The educational theory of Gramsci in the English Language provavelmente escrito em 1977 e no qual trata do tardio interesse por Gramsci na Inglaterra. Segundo ele: "Em 1976, Brian Simon, comparando os problemas da teoria educacional contemporânea com o marxismo dedicou algumas páginas aos aspectos pedagógicos do pensamento de Gramsci" (Ragazzini, s/d) e essas páginas tinham o caráter de uma apresentação bem balanceada e inicial. De acordo com Ragazzini, foi então que começou uma primeira circulação em língua inglesa das reflexões de Gramsci sobre educação. Interessante notar, porém, que em 1965, a New Left 
Review havia publicado a tradução de Per la ricerca del principio educativo, que, no entanto, não se constituiu em marco dos estudos sobre Gramsci na Inglaterra nem o nascimento de um interesse pelos componentes educacionais de seu pensamento. Quanto ao artigo de Brian Simon, foi publicado em 1976 na revista Marxism Today com o título Contemporary Problems in Educational Theory e aborda principalmente a relação entre professor e aluno e os princípios da escola ativa. Metodologicamente, Brian Simon cita excertos de Gramsci e ao final de cada citação faz considerações, algumas vezes concordando, outras vezes questionando, mas em geral, enfatizando a importância de sua teoria para o entendimento da educação como fator de mudança, como se lê:

Gramsci deu imensa ênfase ao papel dos professores, sustentando que a transformação da educação era tanto uma questão de pessoas, dos professores e de quem eles eram, como também de todo o complexo social, como novos currículos e métodos - ou seja, de programas e projetos (SIMON, 1976, p. 176-177).

Nessa perspectiva, ele enfatizou o ativismo como um importante e necessário princípio educativo, mas sem diminuir o papel do professor. Em outro artigo, rejeitando o determinismo e tratando da relação entre base e superestrutura da sociedade, Brian Simon advertiu contra a visão mecânica citando Marx:

Ele reconheceu que a luta de classes se reflete na luta ideológica, para que novas classes desenvolvam sua própria perspectiva ideológica e lutem para alcançar a hegemonia (para usar uma expressão da moda), assim como os franceses enciclopedistas fizeram antes da Revolução Francesa e os marxistas fizeram na Rússia antes de 1917 (SIMON, 1977, p. 198).

É de se notar que os termos entre parênteses "para usar uma expressão da moda" para referir-se ao processo de construção de hegemonia, um dos mais importantes princípios do pensamento de Gramsci, parecem ter sido usados aqui como um reconhecimento de sua influência no final dos anos de 1970 na Inglaterra, embora ela não fosse a chave do seu marxismo.

No entanto, em outro documento, uma espécie de resenha não publicada, Brian Simon defende o marxista italiano e critica a visão de Harold Entwhistle que, consultando intérpretes italianos como Manacorda, publicara, em 1979, um dos primeiros livros em língua inglesa sobre a concepção de educação de Gramsci. Intitulado "Antonio Gramsci: conservative schooling for a radical police", o livro explora temas clássicos da sua pedagogia com atenção particular aos aspectos relacionados ao anti-espontaneísmo e conclui com críticas, já que, para o autor, a concepção de educação de Gramsci era conservadora. Dois aspectos adicionais são interessantes quanto a esse texto de Brian Simon: o primeiro é que ele cita o nome de Manacorda algumas vezes para criticar Harold Entwhistle pelo recurso metodológico a intérpretes de Gramsci. O segundo é que, provavelmente, ao analisar o livro de Entwhistle manifestando-se favoravelmente a Gramsci, Brian Simon o tenha feito por influência de seu irmão Roger Simon, que na mesma época elaborava o seu próprio livro sobre o autor. A propósito, Clyde Chitty; afirmou não acreditar que houvesse tal influência gramsciana no pensamento de Brian Simon, em contraposição à teoria russa da psicologia da aprendizagem, que havia sido fundamental. 
Quanto a Roger Simon, de fato, foi um grande estudioso de Gramsci desde os anos de 1950 e publicou o seu livro em 1982 com o título “Gramsci's Political Thought: an Introduction" tornando-se um dos principais autores sobre o seu pensamento na Inglaterra. Fontes do arquivo do Instituto de Educação mostram a atenção dispensada por Brian Simon aos trabalhos do irmão. Uma dessas evidências está na pasta denominada "Austrália". Entre os materiais nela armazenados para cursos ministrados em 1981 consta um capítulo desse livro, que ainda não estava publicado, além do artigo Gramsci's concept of hegemony que Roger Simon havia publicado em Marxism Today em 1977.

O mais surpreendente, porém, foi constatar nos documentos do arquivo evidências de que na mesma época tal influência se manifestava também em alguns intelectuais do Leste Europeu. As cartas trocadas entre Brian Simon e Olga Salímova, historiadora da educação russa e sua colaboradora desde 1955, são significativas. Em 1980, ela lhe escreveu:

\begin{abstract}
Estou na Itália e ficarei 30 dias. Vim para ver minha amiga italiana que é professora de língua russa na Universidade de Nápoles. Seu pai, Platone Felice, foi um dos mais íntimos amigos de Gramsci. (...) Estou muito interessada em saber sua opinião: estou certa em encontrar algumas tendências comuns no desenvolvimento da teoria marxista da educação em tempos recentes? Disseram-me que meu artigo é um primeiro pequeno passo na pesquisa sobre estes problemas. Talvez você conheça outros exemplos? Espero encontrar aqui teóricos marxistas do Instituto Gramsci porque estou planejando publicar alguns trabalhos de Gramsci sobre educação (SALÍMOVA, carta, 1980).
\end{abstract}

A intenção de publicar Gramsci continuou sendo assunto de cartas subsequentes. Em uma delas, Olga Salímova comunica a Brian Simon que havia submetido seus escritos ao Departamento de sua Universidade, em Moscou, e insiste em um estudo sobre as várias interpretações marxistas sobre educação. Em novembro de 1982 Brian lhe escreveu:

Certamente, estou interessado em sua publicação sobre Gramsci - muitas congratulações - e, por favor, envie-me uma cópia (...) e tudo que você tiver feito sobre Gramsci. Por falar nisso, meu irmão Roger Simon acaba de publicar um livro sobre Gramsci - uma Introdução. Eu lhe mandarei um exemplar assim que tiver um (ele realmente acabou de ser publicado) (SIMON, carta, 1982).

Não foi possível averiguar se de fato Olga Salímova publicou o que pretendia, pois a seqüência de cartas não registrou o desfecho do assunto. No entanto, os dados encontrados demonstram que foi significativo o seu interesse pelo autor e permitem compreender as contingências da circulação do conhecimento numa época em que as cartas eram um meio importante de comunicação entre intelectuais. Além disso, no caso da Europa, o International Standing Conference for the History of Education (ISCHE) já se constituía em fórum importante para a circulação do conhecimento, o intercâmbio entre pesquisadores e a internacionalização da História da Educação. 


\section{Conclusão}

Até a década de 1980, a circulação de conhecimento entre pesquisadores da História da Educação dependeu mais de iniciativas e esforços individuais. A forma de comunicação principal eram cartas e contactos pessoais, conforme ficou constatado entre Brian Simon e Olga Salímova. A relação de Brian Simon com o bloco soviético explica o seu empenho em aproximar pesquisadores do Leste Europeu ao Ocidente, aspecto evidente na correspondência analisada. Tendo sido um dos fundadores do International Standing Conference for the History of Education (ISCHE) e seu primeiro presidente (1978-1982), Brian Simon realizou essa aproximação e colaborou para a internacionalização da História da Educação.

Nesse movimento entre Leste e Oeste, não encontramos a participação de Manacorda. As suas relações internacionais parecem não ter passado pelo ISCHE e sua projeção internacional foi diferente da de Brian Simon. Esse aspecto é interessante porque Brian Simon alcançou projeção internacional com uma obra dedicada à história da educação da Inglaterra. Este foi sempre o seu objeto de estudo e de ação política. Ele desenvolveu larga relação internacional, inclusive com os países ex-colônias do Império Britânico, e tornou-se o mais importante historiador da educação na Inglaterra criticando a visão liberal, rejeitando a historiografia tradicional que enaltecia como pioneiros da educação os reformadores do século XIX. Para ele, ao contrário, os verdadeiros "pioneiros" da educação eram os trabalhadores e suas organizações políticas (McCulloch, 2011).

Manacorda por sua vez, dedicou-se sobretudo a temas conceituais e filosóficos da educação, não se atendo exclusivamente ao âmbito da Itália. Tornou-se um dos maiores intérpretes de Gramsci e desenvolveu outro tipo de relação internacional. No Brasil, a circulação da sua obra deveu-se à iniciativa de um conterrâneo, depois foi ampliada pelo HISTEDBR, e a partir de então, passou a exercer considerável influência, mesmo que não hegemônica, na forma de interpretação do marxismo aplicado à história da educação. A recepção da sua obra no Brasil começou em uma época em que a internacionalização era iniciativa individual dos pesquisadores e as associações científicas estavam nascendo ou se reorganizando no final da ditadura militar. A própria internacionalização, hoje considerada um valor, não era um aspecto importante e começava a tomar impulso com os avanços crescentes da revolução técnico-científica e da globalização.

As duas trajetórias tiveram em comum o marxismo, a convicção na educação como possibilidade de mudança e a luta pela escola secundária comum. $\mathrm{O}$ engajamento de Brian Simon e de Mario Alighiero Manacorda na resistência ao nazi-fascismo, a adesão ao marxismo e ao Partido Comunista de seus países foram atuações típicas dos intelectuais de esquerda do século XX. A esse respeito, assinalou Manacorda: "Sou um homem do século XX, não posso negar as minhas convicções, vou morrer comunista" (Manacorda, 2012).

Quanto à forma de interpretação do marxismo, ficou evidente que tanto Brian Simon quanto Manacorda rejeitaram a visão determinista e compreenderam a educação como possibilidade de mudança enfatizando a flexibilidade da relação entre ela e a sociedade. No entanto, esse aspecto ficou mais visível e recorrente no primeiro, que criticou sistematicamente as interpretações de Althusser, Bowles e Gintis.

No tocante ao pensamento de Gramsci, ele não influenciou a interpretação de Brian Simon, pois a sua campanha pela "comprehensive school" e o combate ao reino da psicometria transcorriam desde o fim dos anos de 1940 e, como vimos, o autor só foi traduzido na Inglaterra na segunda metade da década de 1970. 


\section{Referências}

CHITTY, Clyde. Depoimento. Londres, 30 de janeiro, 2012.

ENTWISTLE , Harold. Antonio Gramsci. Conservative schooling for a radical politice. Routledge \& Kegan Paul, 1979.

HOBSBAWM, Eric. Gramsci and political theory. Marxism Today, London, July 1977.

MANACORDA, Mario A. História da Educação: da antiguidade aos nossos dias. Tradução Gaetano Lo Monaco. São Paulo: Cortez, 1989.

MANACORDA, Mário A. Aos educadores brasileiros. Entrevista concedida a Paolo Nosella. Campinas: HISTEDBR, 2007.

MANACORDA, Mario Alighiero. Depoimento. Roma, 12 junho, 2012.

MANACORDA, Mario Alighiero. Depoimento. ANDE. São Paulo, N. 10, 1986. p. 59-64.

MANACORDA, Mario Alighiero. La mia scuola sotto il fascismo. In: GENOVESI, Giovanni. C' ero anchi'io! A scuola nel Ventennio. Ricordi e riflessioni. Liguori Editore, Napoli, 2010. P. 27-47.

McCULLOCH, Gary. The Struggle for the History of Education London: Routledge, 2011. McCULLOCH, Gary. A people's history of education: Brian Simon, the British Communist Party and Studies in the History of Education, 1780-1870. History of Education, 2010.

RAGAZZINI, Dario. The Educational Theory of Gramsci in the English Language. Brian Simon's Archive. Institute of Education, SIM/6/3/2.

SALIMOVA, Olga. Letter to Brian Simon, 15.5.1980. Brian Simon's Archive. Institute of Education. SIM/2/4.

SIMON, Brian. Letters on Bowles and Gintis's book. Brian Simon's Archive. Institute of Education. London. SIM/1/55.

SIMON, Brian. Does Education Matter? London: Lawrence and Wishart Ltd., 1985.

SIMON, Brian. A Life in Education. London: Lawrence \& Wishart Ltd, 1998.

SIMON, Brian. Contemporary problems in educational theory. Marxism Today, June, 1976.

SIMON, Brian. Marx and the crisis in education. Marxism Today, July, 1977.

SIMON, Brian. Letter to Olga Salimova. 28 November, 1982. Brian Simon's Archive. Institute of Education. SIM/2/4.

SIMON, Roger. Gramsci's Political Thought: an Introduction. London, Lawrence and Wishart, 1982.

Roger Simon. Gramsci’s concept of hegemony. Marxism Today. March, 1977.

\footnotetext{
Notas:

${ }^{1}$ Doutora em História Social pela Universidade de São Paulo; professora-visitante na Universidade de Londres, Instituto de Educação (IOE); professora da Graduação e da Pós-Graduação em Educação da Universidade Federal de São Carlos (UFSCar). Pesquisadora do CNPq.

${ }^{2}$ Segundo depoimento do Professor Clyde Chitty, no Instituto de Educação da Universidade de Londres, o contexto político do final da década de 1980 e a delicada situação política da União Soviética, que acabaria resultando no fim do "socialismo real" influenciaram a decisão de Brian Simon pela publicação de uma parte apenas de sua autobiografia. No passado, ele havia sofrido hostilidades por essa relação, inclusive no ambiente acadêmico, e levou em consideração a opinião de sua esposa, Joan Simon, historiadora da educação como ele, de publicar apenas a sua trajetória na educação. CHITTY, Clyde. Entrevista. Londres, 30 de janeiro, 2012.

${ }^{3}$ Todas as traduções de fontes inglesas citadas no artigo são de minha autoria e responsabilidade.

${ }^{4}$ Ver: McCULLOCH, Gary; WOODIN, Tom (2010): Learning and liberal education: the case of the Simon family, 1912-1939. Oxford Review of Education, 36:2, 187-201. Nesse artigo, os autores fazem interessante estudo sobre os moldes e valores da educação liberal examinando o caso específico da família Simon.

Recebido: Fevereiro-2013 Aprovado: Março-2013
} 